getting more general users," says Françoise Delplancke, head of the interferometry group for the European Southern Observatory's Very Large Telescope Interferometer (VLTI) in Chile. The number of science papers based on optical interferometry has surged as well, from 9 in 1999 to 56 last year. The VLTI, the focus of European support, is responsible for about half of those.

The support for US facilities is more fragmented. CHARA is a university-run operation supported by the National Science Foundation. A potential rival, the Magdalena Ridge Observatory in New Mexico, has run into delays because of funding problems. A NASA-supported interferometer involving the twin 10-metre Keck telescopes in Hawaii was supposed to achieve VLTI-like capabilities with the addition of four to six small 'outrigger' telescopes. But the auxiliary project was derailed in 2006 over environmental and cultural concerns about building new telescopes on the Mauna Kea summit.

Yet not everyone has given up on Mauna Kea, which holds the largest concentration of huge telescopes on Earth. Guy Perrin, an astronomer at the Paris Observatory and principal investigator for the Optical Hawaiian Array for Nano-radian Astronomy (OHANA), is connecting the seven large telescopes at the summit into an array with a baseline of 800 metres. As a proof of principle, Perrin has already combined light from the two Keck telescopes via inconspicuous optical fibres, which would obviate the need to connect the telescopes with tunnels ${ }^{3}$.

Reached by telephone atop the summit, Perrin last week was busy implementing a second stage - a fibre-optic link to connect the Gemini North telescope to the CanadaFrance-Hawaii Telescope. Down in Chile, at the VLTI, he is helping to develop integrated optics, which would combine beams efficiently on tiny silicon chips rather than in large, complicated rooms.

Although the technological hurdles to the OHANA project are still high, Perrin says that a bigger problem could be getting all the Mauna Kea observatories to simultaneously offer up their telescope time - a precious and fiercely guarded resource. "It will be easier to convince the communities that are behind the telescopes," says Perrin, "if we first demonstrate that interferometry is a big player in science today."

Eric Hand

1. Kloppenborg, B. et al. Nature 464, 870-872 (2010)

2. Monnier, J. D. et al. Science 317, 342-345 (2007).

3. Perrin, G. et al. Science 311, 194 (2006).

\title{
Charities warm to climate
}

to commercial investment in clean energy

Global steps to battle climate change might have faltered, but philanthropic institutions in the United States have swung into action, more than tripling their support for climaterelated causes in 2008. Donations jumped from the 2007 total of US $\$ 240$ million to \$897 million in 2008 (see 'Climate concern'), according to a report from the Foundation Center, an organization that supports philanthropies, in New York.

The funding is going to a range of activities, including efforts to reduce greenhouse-gas emissions and to prepare cities for warmer temperatures and higher sea levels. Foundation money is also supporting academic researchers studying the effects of climate change and ways to reduce pollution. In 2008, for example, the Rockefeller Foundation in New York gave a grant to Stanford University in California for studies on how agriculture could adapt to a changing climate. The ClimateWorks Foundation in San Francisco, California, is supporting research around the world, including a grant to Wang Lan, a materials scientist at the China Building Materials Academy in Beijing, who is working to reduce greenhouse-gas emissions from cement production.

The vast majority of the increase in 2008 came from the William and Flora Hewlett Foundation in Menlo Park, California, which gave a total of \$549 million. Hewlett's donations included a one-time contribution of $\$ 500$ million to ClimateWorks, which aims to help countries limit carbon dioxide concentrations in the atmosphere to less than 450 parts per million.

Many other foundations also bumped up their spending. All told, 267 foundations other than Hewlett distributed 1,578 grants for climate change, representing a $45 \%$ increase in their giving compared with 2007, according to the Foundation Center report, which is entitled Climate Change: The U.S. Foundation Response.

A generational change may account for part of the sudden generosity. Baby boomers are showing more concern about climate change than previous generations did, says Rachel Leon, executive director of the Environmental Grantmakers Association in New York, a trade group of environmentally focused foundations. These people are now starting to set up their own foundations with a strong emphasis on climate change.

The efforts of the foundations pale next
- $\$ 173$ billion in 2008 and $\$ 162$ billion last year, according to market analysts Bloomberg New Energy Finance in London. But foundations can fund projects regardless of their potential pay-off, says Ethan Zindler, the company's head of US research. "They view it as a social imperative," he says. ClimateWorks, for example, collaborates with smaller foundations around the world on projects including the development of vehicle-fuel standards in India and appliance standards in China.

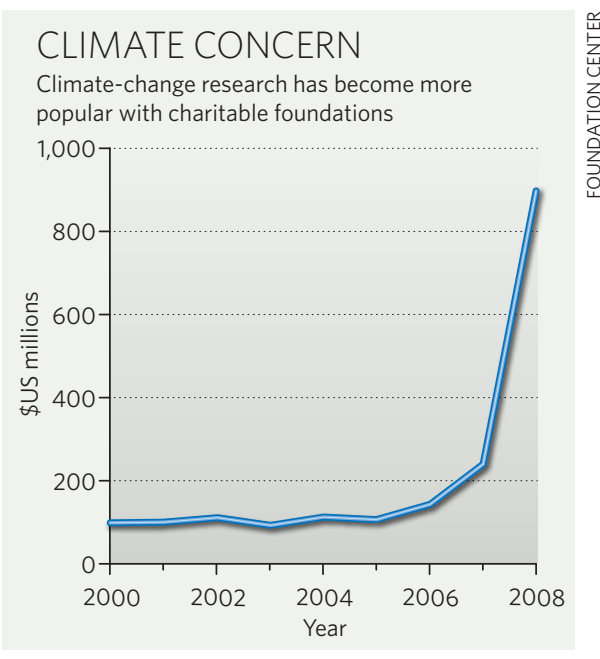

Other efforts aim to help developing countries adapt to change. Under a fiveyear, \$70-million commitment in 2007, Rockefeller established the Asian Cities Climate Change Resilience Network, which focuses on aiding smaller cities, such as Surat in India, make growth decisions that help them survive a shifting climate. "We are not really an environmental foundation but a poverty-reduction foundation. But we see a connection between them," says Cristina Rumbaitis del Rio, an associate director at the Rockefeller Foundation.

None of the foundations contacted by Nature would say what it plans to give in 2010. Because Hewlett will not repeat its \$500-million, one-time donation, the total foundation support for climate-related causes is likely to drop from its 2008 high, but Steven Lawrence, the director of research for the Foundation Center and the author of the new report, expects funding this year to surpass the 2007 amount. "My expectation is to continue to see growth in giving." Laura Thompson Osuri 